\title{
Examination of disappeared Kaybolan çocuk oyunlarının children's games in culture kültür ve çevre bağlamında and environment context: incelenmesi: Sarıkeçili yörük Sarıkeçili yörük example örneği
}

\author{
Ferhat Büyükşahin ${ }^{1}$
}

\begin{abstract}
The games of children in Sarkkeçili Yoruk community and the reasons of the disappearance of these games because of environmental factors are studied in this research. Time, place and children are required for the games, which have positive effect on children's personal developments, to be played. It is obvious that disappearance of the games played is inevitable in the case of loss of one of these conditions. Participant observation method which is one of the qualitative researches is used for this study. Detailed oral interviews have been done as the observation of the children's many games not been played recently in Sarrkeçili Yoruk community, who is still having nomadic life, because of different effects. It is also observed that the children's games played until 1985s is remembered by the ones over middle ages and these games types are almost to forget. The places of this research consists of the small cities Silifke, Aydincık, Gülnar, Bozkır, Hadim, Seydişehir which are the habitats of Sarıkeçili Yoruk community having nomadic life. In this research, how the children's games, which have an important part for the culture to combine the community, were preserved and how it is blocked to hand down to generation to generation by the environmental factors are studied. Records about socio-cultural practices of recent nomads
\end{abstract}

\section{Özet}

$\mathrm{Bu}$ araştırmada, kültür ve çevre bağlamında Sarıkeçili yörüklerde oynanan çocuk oyunlarının - çevresel faktörler ile kaybolma nedenleri incelenmiştir. Çocukların kişisel gelişiminde pozitif katkılar sağlayan oyunların oynanabilmesi için zamana, mekana ve çocukların bir arada olabilmesine ihtiyaç vardır. Şartlardan herhangi birinin eksikliği durumunda toplu olarak oynanan oyunların yok olacağ1 değerlendirilmektedir. Bu çalışmada nitel araştırma tekniklerinden olan 'katılımcı gözlem metodu' uygulanmıştır. Göçebe hayat süren Sarrkeçili Yörük Topluluğu'nda birçok çocuk oyunlarının değişik etkenlerden dolayı günümüzde oynanmadiğ1 gözlemlenmiştir. Bu nedenle çocuk oyunlarının kaybolma nedenlerini ortaya koyabilmek için derinlemesine mülakatlar yapılmıştır. 1985'li yıllara kadar oynanan çocuk oyunlarının, sadece orta yaş üzeri kişilerin hafizasında kaldığ1 ve bu hatırlanan oyun türlerinin de unutulmaya yüz tuttuğu gözlemlenmiştir. Araştırmanın evrenini, günümüzde hala konar-göçer yaşamı devam ettiren Sarnkeçili Yörük Topluluğu'nun yaşam yerleri olan, Silifke, Aydıncık, Gülnar, Bozkır, Hadim, Seydişehir ilçelerinin kırsalı oluşturmaktadır. $\mathrm{Bu}$ araştırmada toplum üzerinde birleştirici rol oynayan kültürün çok önemli bir parçası olan çocuk oyunlarının geçmişten günümüze kadar bozulmadan nasıl 
Büyükşahin, F. (2018). Kaybolan çocuk oyunlarının kültür ve çevre bağlamında incelenmesi: Sarıkeçili yörük örneği. Journal of Human Sciences, 15(2), 881-892. doi:10.14687/jhs.v15i2.5063

alanlarda yeni otlak ve su bulma periyodu içerisinde kültürün biçim bularak yaşam pratiklerine dönüştüğü görülmektedir (Deer, 1954).

Anadolu'nun coğrafi yapısı da geçmiş yüzyıllarda olduğu gibi pastoral göçebe kültürüne uyumlu bir yapı sergilemektedir. Bu coğrafyada göçebe kültürün gelişmesine katkı sağlayan toplulukların başında "Yörükler" gelmektedir. Yüzlerce yıllık kültür birikimlerini kapalı bir topluluk olmalarından dolayı daha az bozulmaya maruz kalarak günümüze kadar taşımışlardır. Kutlu (1992), Anadolu coğrafyasında yaşamakta olan göçebe çok fazla bir değişikliğe uğramadan sürdürebilmesinin nedenini, aşiret tipi yapılanmalarından kaynaklanan örgütlenmeye ve kan bağlarını devam ettirirken, geniş akrabalık bağlarına dayanan gelenekçi, kapalı ve cemaat tipi topluluklar olmalarına bağlamaktadır. Göçebe kültürün başlangıç aşamasının, yazılı tarihten önce kronolojik sıraya göre ele alındığında toplayıcılık, avcılık; hayvanların evcilleştirilmesi ile birlikte hayvancılık, tarımın keşfedilmesiyle birlikte yarı yerleşik hayat ve çiftçilik şeklinde dönüştüğü gözlenmektedir (Büyükşahin ve Güneş, 2016; Büyükşahin ve Güneş, 2017; Sayllır, 2012). Bütün bu değişim süreci olmasına rağmen Anadolu'da bulunan pastoral göçebe toplulukları oluşturan yörükler ana kültüre bağlı alt kültür olarak varlıklarını devam ettirmektedirler (Kutlu, 2000).

Göç; genel anlamıyla yaşam alanının değiştirilerek başka bir yaşam alanının seçilmesidir. Değissik nedenler ile yapılan göçleri şu şekilde sıralamak mümkündür; ekonomik nedenler ile göç, politik nedenlerle göç, savaş nedeniyle göç, kişisel ihtiyaçlar doğrultusunda göç (Bulut, 2017) olmak üzere daha birçok nedenler sıralanabilir. Sarıkeçili Yörüklerin göç etme nedenlerinin dinamik yapısını, ekonomik nedenler oluşturmaktadır. Sarıkeçili Yörükler geçmiş dönemlerde toplu yaşam alanları bulabilmişler ve kültürel etkileşimlerini üst düzeyde gerçekleştirebilmişlerdir. Günümüzde ise göç yolları değişik nedenler ile oldukça daralmıştır. Öyle ki bazı yörelerde kapanmış buna istinaden alternatif göç yolları bulunmuştur. Göç yollarının daralmasından ve kapanmasından önce, çayır ve meraların bol olduğu dönemler yaşanmaktaydı. Bu dönemlerde Sarnkeçili Yörüklerin çocukları da geniş oyun alanlarına sahipti. 1985 yllına kadar çocuklar boş vakitlerde bir araya gelerek, çevresel etkilerin de sunduğu şartlara göre çocuk oyunları oynayabilmişler ve bulundukları koşullara göre oyunlarını geliştirebilmişlerdir. Lakin 1985 yılından sonra Çayır ve meraların tarım arazilerine ve orman gençleştirme sahalarına dönüşmesi ile birlikte göç yollarının daralmasına ve neticesinde toplu hareket etme kabiliyetlerinin kaybolmasına neden olmuştur. Geleneksel kültürün bir parçası olan çocuk oyunlarını da bu olumsuz gelişmelerin neticesinde kaybetmeye başlamışlardır.

\section{Yöntem}

$\mathrm{Bu}$ araştırma ile kapalı cemaat tipi özelliği gösteren Sarıkeçili Yörüklerde unutulmaya başlayan çocuk oyunlarının ortaya çıkartılması amaçlanmıştır. Cemaat tipi kapalı toplumlarda kültürel değişim ve kültürel bozulmalar kentlere oranla çok daha geç olmaktadır. Bu nedenle Sarıkeçili Yörüklerde oynanan oyunlar çok uzun yıllar devam ettiği ve günümüze kadar ulaştı̆̆1 değerlendirilmektedir. Bu durum ise Türk kültürünün geçmişten günümüze özelliğinin bir yanını gösterdiği için oldukça önemlidir. Giriş bölümünde de bahsedildiği gibi Sarıkeçili Yörüklerde oynanan çocuk oyunlarının kültürün bozulmasından olmayıp çevresel nedenlerden kaynaklandığ1 tespit edilmiştir. 1985 yıllarında yapılan orman ve mera düzenlemeleri, Sarıkeçili Yörüklerin bir arada yaşamasına mani olmuştur.

Araştırmanın yöntemi sahada gözlem yolu ile gerçekleştirildiği için nitel bir çalışmadır. Bu çalışma, Sarıkeçili Yörüklerin kışlak olarak kullandıkları Erdemli, Silifke, Mut, Aydıncık bölgelerinde ve yazlak olarak kullandıkları Hadim, Bozkır, Ermenek ve Seydişehir kırsalında gerçekleştirilmiştir. Sarıkeçili Yörüklerin yaşam alanlarının dağlık olması, ulaşımın arazi tipi olmayan araçlara pek fazla müsaade etmemesi, topluluğun bir birlerinden oldukça uzak mesafelerde ve dağınık şekilde yaşaması gibi nedenler ile gurubun tamamına ulaşmak mümkün olmamışır. Bu nedenle Sarıkeçili Yörüklerin tüm özelliklerini yansıtacak örneklem gurup seçilmiştir. Örneklem gurup ile yapılan görüşmeler çocukları, orta yaşlları ve orta yaş üstünü oluşturacak şekilde düzenlenmiştir. Gurup, katıllimc1 gözlem metoduyla gözlemlenmiştir. Nitel çalısmalarda derlenen bilginin veri değerini artıran önemli konulardan birisi de çalışmanın yapıldığı tarihlerdir (Barzun ve Graff, 2008). Gelecek kuşaklara ve 
Büyükşahin, F. (2018). Kaybolan çocuk oyunlarının kültür ve çevre bağlamında incelenmesi: Sarıkeçili yörük örneği. Journal of Human Sciences, 15(2), 881-892. doi:10.14687/jhs.v15i2.5063

araştırmacılara bilimsel bir veri özelliği kazandırır. Bu bağlamdan hareketle, katılımcı gözlem metodunun uygulandığı bu çalışma, 2015-2018 yılları arasını kapsayacak şekilde üç yıl sürmüştür. Saha çalışmaları sırasında yeni yetişen çocukların 1985 yıllarına kadar oynanan çocuk oyunlarından uzak olduğu görülmesi ile birlikte derinlemesine mülakatlar yapılmış ve geçmiş dönemlerde oynanan çocuk oyunları tespit edilmeye çalışılmıştır. Ayrıca söz konusu bu oyunların bazıları temsili olarak canlandırılması istenmiştir. Görüşme guruplarından izin alınarak bazı oyunlar görüntülü kayıt altına alınırken, bazıları ses kaydına alınmış, gelecek kuşaklara ve araştırmacılara bilgi niteliğinde arşiv oluşturulmaya çalışılmıştır.

\section{Sarıkeçili yörükleri}

Türkler Orta Asya steplerinden değişik nedenlerden dolayı göç etmişlerdir. Anadolu yörük toplulukları için elverişli bir coğrafi yaşam alanı ve imkanı sunduğu için ise XI. Yüzyılda toplu olarak göç etmişlerdir (Büyükşahin, 2017). Sarıkeçili Yörükler de Orta Asya'dan Anadolu'ya gelen göçebe Türk aşiretlerindendir. Oğuzların 24 kolu olan Kayı Boyu'nun alt kolundan birisidir. Cumhuriyet’in ilk yllarında Akdeniz sahillerinde konar-göçer yaşama devam etmişlerdir. İskan politikaları neticesinde birçok yörük topluluğu yarı yerleşik hayata geçmiş ve yaylacılık faaliyetlerine devam etmişlerdir. Ana geçim kaynaklarını hayvancılık oluşturmaktadır. Yayla ve sahil arasında yapılan göçün temel dinamik yapısını ekonomik koşullar oluşturmaktadır. Geçen zaman içerisinde tarımsal faaliyetler ağırlık göstermiş ve hayvanclık birçok yörük tarafindan terk edilmiştir. Ancak Sarıkeçili Yörüklerin yaklaşık 180-200 çadırlık bir topluluğu şekil 1'de görülen Erdemli, Silifke, Gülnar, Aydıncik ve Mut bölgelerinde konar-göçer yaşama devam etmektedir.

Şekil: 1 Sarıkeçili Yörüklerin yaşadıkları kışlak alanlar

KIŞLAK ALANLAR (Gülnar, Silifke, Erdemli)

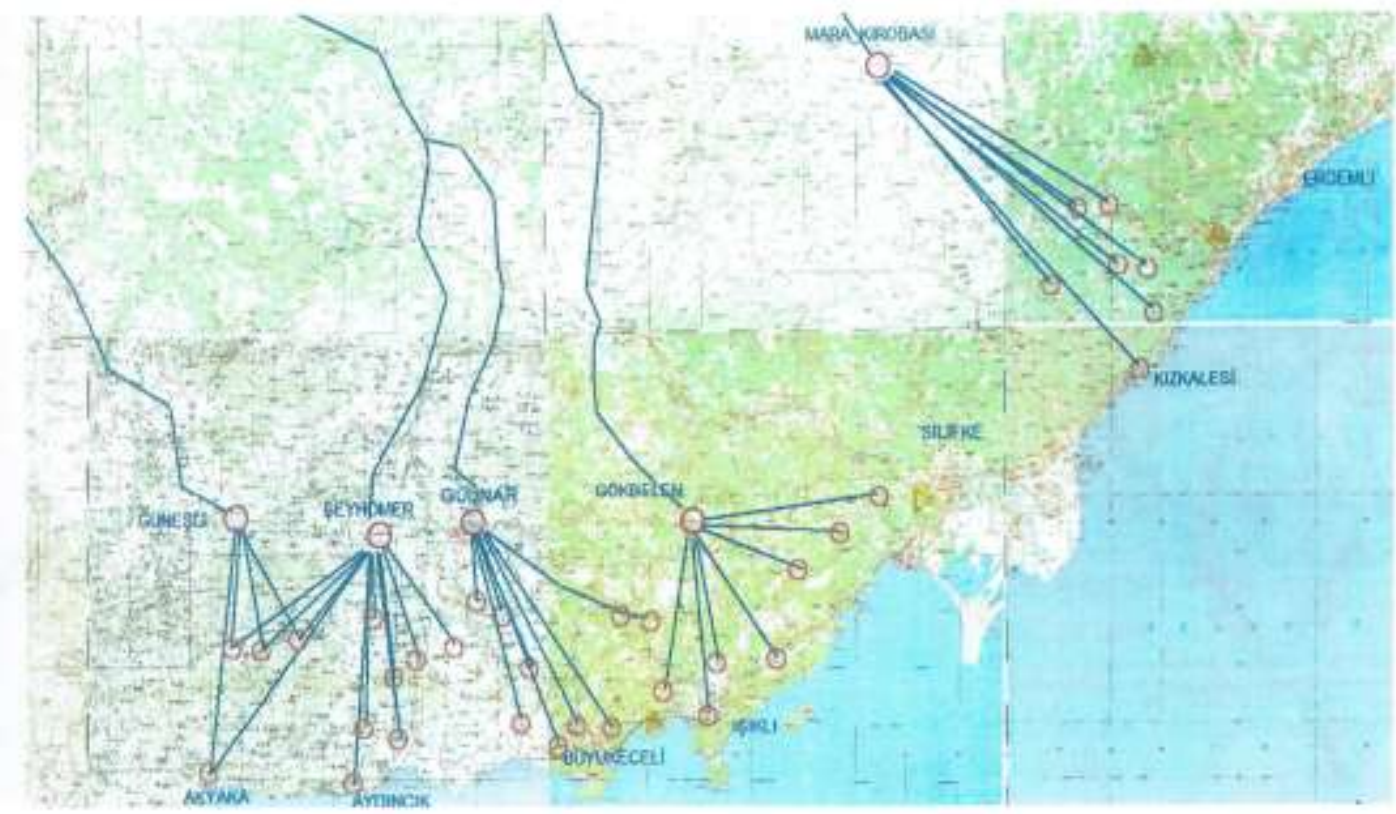

Kaynak: Mersin Orman İşletme Md.lüğü

Kış1 1lıman iklime sahip bu bölgelerde geçiren Sarıkeçililer yaz dönemlerinde Ermenek, Hadim, Taşkent, Bozkır ve Seydişehir kırsalına çıkmaktadırlar. Yazlak, güzlek ve kışlak arasında belirli periyotlar halinde otlaklardan istifade eden Sarıkeçili Yörükler ekolojik dengenin korunmasına da son derece katkı sağlamaktadırlar.

Sarıkeçili Yörükler kapalı bir topluluktur. Kesin bir kural olmamakla birlikte 'endogami' denilen içte evlilik hakimdir. Bu nedenle kültürel bozulma kentlerde yaşayanlara oranla çok daha yavaş gerçekleşmektedir. Orta Asya'dan Anadolu'ya getirilmiş birçok kültürü günümüz şartlarında 
Büyükşahin, F. (2018). Kaybolan çocuk oyunlarının kültür ve çevre bağlamında incelenmesi: Sarıkeçili yörük örneği. Journal of Human Sciences, 15(2), 881-892. doi:10.14687/jhs.v15i2.5063

da yaşatmaya devam ettirmektedirler. Çocuk oyunları da yaşatılan kültürlerden sadece bir tanesidir. Bu kadar uzun yıllar yaşatılarak günümüze taşınmış bu oyunlar geçmis hakkında bilgi yansıtması açısından önemlidir. Bu araştırmanın alt bölümlerinde Sarıkeçili Yörüklerin çevresel faktörleri de kullanarak kendi oyun türlerini nasıl oluşturdukları, boş vakitlerini nasıl değerlendirdikleri, çevresel etkilerin kısıtlaması ile oyunların nasıl azalışa geçip kaybolduğu incelenmiştir.

\subsection{Sarıkeçili yörüklerde oynanan çocuk oyunu örnekleri:}

Sarıkeçili Yörükler, geçmiş yıllarını anlatırken duygulanmaktadırlar. 1985 yılından sonra doğan çocukların ise neredeyse hiç çocuk oyunları oynamadığını ifade etmektedirler. 1985'li yıllara kadar yörükler toplu halde yaşayabildikleri için sosyal iletişim daha güçlü yaşanabilmiştir. İskân sorunun artması ile birlikte, oba anlayışının bozularak yalnızlığa itilmeleri sosyal iletişimin çözülme sürecini başlatmıştır. Diğer bir etken ise teknolojinin gelişmesidir. Teknolojinin gelişmesi ile birlikte kitle iletişim araçlarının artması, sosyal çözülmenin başlangıcını hızlandıran diğer etken olduğunu ifade etmektedirler. Radyonun yaygınlaşması ile iletişim azalarak kişilerin bireyselliğe doğru ilerlediği belirtilmektedir. Televizyonun insanların hayatına girmesi ile birlikte iletişim, diyalog, oyunlar daha da azalmıştır. Son dönemlerde akıllı telefonlanın kullanılmaya başlanması ve sosyal medyanın yaygınlaşmış olmasının tüm ilişkileri neredeyse bitirme noktasına getirdiğini anlatmaktadırlar. Cep telefonu, gençler ve otuzlu yaşlara kadar olan orta nesilde eğlence amaciyla kullanılan en önemli iletişim aracı haline dönüşmüştür. Birçok kültürün şekil değiştirmesi ve yok olması gibi, çocuk oyunu kültürünün de bitme noktasına gelmiş olduğu gözlemlenmiştir.

Geçmiş yıllar Sarıkeçili Yörük çocuklarının kış yurdunda akşamı zor ettikleri dönemlerdir. Çadırların birbirlerine olan mesafesinin bugünlerde olduğu gibi çok uzak olmadığı dönemlerdir. Güneşin batımı ile birlikte akşam yemeğini yiyen çocuklar meydana çıkmaktadır. Meydana çıktıklarını ifade etmek için melodik tarzda 1slık çalınmaktadır. Islı̆̆ duyan diğer çocuklar ve gençler meydana koşmaktadır. Meydanda çoklu oyunlar oynanabildiği gibi, küçük grupların oynadığ1 oyunlar da bulunmaktadır. Bir diğer grup da oynanan oyunları seyretmekle eğlenmektedir. $\mathrm{Bu}$ oyunlardan bazıları ise aşağıda anlatıldığı gibidir.

3.1.1. An taşı oyunu: Oyun, altı kişi ile oynanır. Oyunun keyfi ise seyirci sayısının çokluğu ile artar. Ortaya "an" taşı denilen bir taş koyulur. Oyunculardan iki tanesinin elini ayağını bağlarlar. Tostoparlak olan oyuncu kıpırdayamayacak şekle gelir. Oyunun oynanacağı alanın orta kısmına bu elleri ayakları bağlanmış oyuncuları oturturlar. An taşı bu iki şahsın arasında kalır. Ortada bulunan an taşı sınırı temsil eder. Bu sınır taşının bekçisi de elleri ayakları bağlı olan kişilerdir. Her iki oyuncu gurubu, bu taşı kendisine sınır olarak bilir. Oyunculardan bir tanesi, sırtına kendi arkadaşlarından bir tanesini bağlar. Rakip oyuncu da aynı şekilde arkadaşlarından birisini kendi sırtına bağlar. Oyuncular ellerine bir buçuk metre uzunluğunda bir sopa alırlar. Ancak bu sopanın uçları oldukça sivri hale getirilmiştir. Her iki oyuncunun da elinde çemberden (tülbent) yapılmış adına "tura" denilen malzeme bulunur. Bu çember iki kat yapılıp örgü şeklinde sert bir şekle dönüşür. Tura o kadar sertleşmiş̧ir ki, adeta kaya gibi olmuştur. Oyuncuların dışında kalanlar seyircidir. Yaklaşık $6 \mathrm{~m}^{2}$ bir alana seyirciler yerleşir. Oyuncular bu seyircilerin önünden geçerken sorarlar: 'Nereye gidiyorsun?' derler. Oyuncu 'Hacı'ya gidiyorum.' der. Seyirciler, oyunculardan Hacı'dan tespih, boncuk, koku vb. eşya getirmelerini isterler. Oyuncular 'Tamam' derler. Yörük bir miktar seyircilerden uzaklaşıp geri döner. Seyirciler: 'Getirdin mi benim siparişimi?’ diye sorarlar. Oyuncu, “eyvah biç sorma ya, benim eşek kafam unutmusum ya, nasıl bir kafam var, vay beni vay" der ve elindeki taş kadar sert olan turayı arkasında bağlı olan arkadaşının başına başına vurur. Cezayı çeken arkadaki şahıs olur. Oyuncu "ya hacıya gittim idi cok yoruldum ya, bi dinleniin" der ve elinde bulunan sivri uçlu sopayı yere dayar. Sivri ucunu ise arkasında bulunan arkadaşının kaba etine denk getirir ve onun üzerine doğru yaslanır. Arkada bulunanın canı yanar. Kıpırdamak ister. Ancak kıpırdadıkça sivri sopa daha da batar. Seyirciler bu halden o kadar keyif alırlar ki gülmekten gözlerinden yaşlar gelir. Oyuncu "Tamam dinlendim" der sopasını eline alarak ilerler. Orta yerde bulunan an taşının yanına varır. Orada bulunan bekçiye sorar. "Ben bu taşı sana emanet ettiydim. Sen niye bu taşın yerini değiştirdin" der. Öfkelenmiş gibi yaparak taşı kendi tarafina doğru çekmeye çalışır. Tam o esnada karşı tarafta bulunan oyuncu da durumu görür. "O taş bu taraftaydı nereye götürüyorsun?” der ve heyecan başlar. İlk taşı alan oyuncu: 
Büyükşahin, F. (2018). Kaybolan çocuk oyunlarının kültür ve çevre bağlamında incelenmesi: Sarıkeçili yörük örneği. Journal of Human Sciences, 15(2), 881-892. doi:10.14687/jhs.v15i2.5063

"Sen neyine güveniyon da taşı alyyon" der. Diğer oyuncu da: "Arkama güveniyorum” der ve sırtını döner. Diğer oyuncu elinde bulunan turayı, arkasını dönmüş oyuncunun sırtına sırtına vurur. Sırtına vurulan oyuncu geri döner. "Peki sen nerene güveniyorsun?" der. O da aynı cevab1 verir. "Ben de arkama güveniyorum” der ve arkasını döner. Bu sefer, kendisinin arkasında bulunan arkadaşının sırtına vururlar. Sonra bekçiye gelirler. 'Sen benim “an”ıma niye bakmadın?' diye hesap sorarlar. “Ben hacıya gitmistim, sen neden emanete sahip ģkmadın?" derler. Ellerindeki sopayla her iki oyuncu da bekçiyi sırtına vurarak sopalarlar. Elleri bağlı olan bekçiye türlü eziyet ederler. Seyirciler gülmekten göz yaşlarına hakim olamazlar. Daha sonra oynanacak An taşı oyununda oyuncular yer değiştirir. Böylece adalet sağlanmış olur. Her oyuncu aynı cezaya maruz kalmış olur.

3.1.2. Balık battı: Kadınların başlarına örtmüş olduğu tülbent, oyuncular tarafından alınır. İki ucundan tutulur. Uçlar ters istikametlerde çevrilerek tülbent sert bir hale getirilir. Tülbent sert bir cop şekline ulaşınca çevirme işlemi biter. Bu materyalin yeni ismi "tura" olmuştur. Oyun kış şartlarında çadırın içerisinde oynanabildiği gibi dışarıda da oynanmaktadır. Oyuncular halka olacak şekilde otururlar. Ebe olan kişi halkanın orta kısmına geçer. Tura kimin elindeyse ortada bulunan ebenin sırtına sert bir şekilde vurup turayı yerde oturan herhangi bir oyun arkadaşına atar. Ebe, turayı kapmak için hızla koşar. Yerde oturanlar dizlerini A harfi şeklinde bükerek turayı bacaklarının altından elden ele ulaştırırlar. Bacakların altından geçtiği için "balık battı" denir. Tura başta oturan kişinin eline ulaştı̆̆ında o kişi kalkar. Ebenin sırtına bir daha vurur. Turayı yeniden bir başkasına atar. Ebe, turayı kimin elinde yakalar ise ebe o olur. Başta bulunan kişi elinde bulunan turayı herhangi bir oyuncuya atarken diğer oyuncuya ulaşmadan ebeye yakalatırsa kendisi ebe olur. $\mathrm{Bu}$ durumda ortada duran kişi ebelikten kurtulmuş olur. Yeni ebe turayı elinde yakalatan kişidir.

3.1.3. Dokurcan (dokuz taş): Birçok yerde "dokuztaş" diye adlandırılan bu oyun, Sarıkeçili Yörükler arasında 'dokurcan' olarak adlandırılmaktadır. Dokurcan oyunu şekil 2'de görüldüğü gibi düz bir zemine çizilir. Oyun iki kişi ile oynanır. Ancak bu oyunda usta olan kişilerin seyircileri de oldukça fazladır. Oyun esnasında herkes sessizce oyunu izler. Yanlış hamlelerde oyuncusuyla alay edilir. Bu nedenle oyuncu büyük bir stres altında kalır. Her oyuncuda dokuz tane taş bulunur. Oyuncuların taşları birbirine karışmaması için farklı cinsten taşlar toplanır. Birisi kayaç taş toplarken diğeri çakıl taşı toplar ve kullanır. İlk oyuncu köşelerden birine taşı koyar. Taş koyma sırası diğer oyuncuya geçer. Rakip oyuncu taşını koyduktan sonra ilk oyuncu strateji geliştirmeye çalışır. Amaç üç tane taşı aynı çizgi üzerine getirebilmektir. Üç taşın aynı çizgi üzerine getirilmesine "guranç" denilmektedir. Üç taşı aynı çizgi üzerine getirebilen oyuncu, rakibinin taşlarından bir tanesini alma hakkına sahip olur. Oyuncular, özellikle üç taşın bir araya gelme ihtimali olan taşı, öncelikli olarak alır ki rakip oyuncunun pozisyonunu bozmuş olsun. Her bir taş yerleştirilirken oyuncular, öncelikli olarak kendi taşlarını en kısa sürede aynı çizgiye üç taşı sıralayabilecek şekilde koyar. Rakip oyuncu ise taşını her seferinde rakibini zor duruma düşürecek şekilde dizer. Oyunda asıl amaç, taşlarını aynı hizaya getirerek rakip oyuncunun taşını bitirmektir. Bazen oyuncular uygun boşluğu bulur. Taşını ileri geri getirerek 'vardı geldi' denilen konuma düşürür. Tek taş nereye hareket ederse guranç meydana gelir. $\mathrm{Bu}$ durumda rakip oyuncu oyunu kaybeder. Kaybeden oyuncu için oyuna başlamadan önce belirlenmiş olan ceza uygulanır. Bu oyun üç taşla oynanabileceği gibi, on iki taşla oynanacak şekilde çizim şekli değiştirilebilmektedir. En yaygın oynanan dokuz taşla olandır.

Şekil 2: Dokurcan oyunu (dokuz taş)

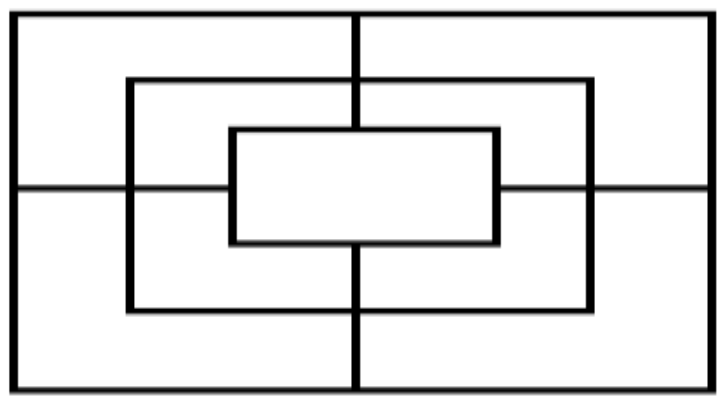


Büyükşahin, F. (2018). Kaybolan çocuk oyunlarının kültür ve çevre bağlamında incelenmesi: Sarıkeçili yörük örneği. Journal of Human Sciences, 15(2), 881-892. doi:10.14687/jhs.v15i2.5063

3.1.4. Kale yıkma: Oyuncuların sayısına göre gruplar en az ikiye tercihen üç gruba ayrilır. Her grup oyun öncesinde belirlenen sayıdaki düz taşlanı üst üste dizer. Kale haline getirilen taşlardan yaklaşık olarak on ile on beş metre uzakta düz bir çizgi çizilir. Gruplar, kaleyi yıkmak için kendilerine düz, atışı kolay bir taş seçerler. Ellerindeki taşları atarlarken bu çizgiyi geçemezler. Her grubun kendine ait atış taşı vardır. Hakemin belirlediği sıraya göre gruplar, ellerindeki taşı kaleye doğru atarak kaleyi yıkmaya çalışırlar. Kaleyi yıkan diğer grubun sırtına biner. Kalelerinin olduğu yere kadar kendilerini taşıttırırlar. Kale yeniden dizilir. Oyun yeniden başlar. Bıkana kadar oyuna devam edilir.

3.1.5. Çelik (çellik) oyunu (çelik çomak): Oyuncular iki guruba ayrılır. Oyuncular, oynayacakları çelik oyununun malzemelerini doğal çevreden elde ederler. $80-85 \mathrm{~cm}$. uzunluğunda düz bir sopa bulurlar. Bu sopaya "çomak" denir. 'Met (Çelik)' denilen 15-20cm uzunluğunda küçük bir sopa daha temin ederler. Metin uç kısımları çapraz gelecek şekilde inceltilerek sivrileştirilir. Toprak zemine $5 \mathrm{~cm}$.lik küçük bir çukur kazarlar. Bu çukura "yalak" denir. Oyuna başlayacak olan takım bu çukurun üzerine meti koyar. Oyuncu uzun çubuğunu, deliğin içerisine metin altına gelecek şekilde koyar. Uzun çubukla karşısında bekleyen rakip oyuncuların üzerine doğru meti mancınık gibi firlatarak gönderir. Rakip oyuncular çeliği yakalar ise ebe olmaktan kurtulurlar. Yakalayamazlar ise meti düştüğü yerden alırlar. Meti atan takım elindeki çomağ1 yere paralel olarak serer. Rakip oyunculardan birisi meti çomağa değdirebilmek için atar. Değerse ebe olmaktan kurtulurlar. Değmez ise oyuncu meti uygun bir pozisyonda yere koyar. Elindeki çomak ile mete kuvvetli bir şekilde vurur. Met havaya kalktığında elindeki sopayla çok kuvvetli vurarak meti en uzak mesafeye göndermeye çalışır. Bu esnada ebe olan takım, meti havada iken yakalayabilirse ebelikten kurtulur. Yakalayamaz ise oyuncular metin düştügü yerden yalağın olduğu yere kadar adımlar. Atılan adımlar birer birer sayllır. Amaç hedeflenen puana ulaşmaktır. Hedefe ilk ulaşan takım rakiplerini yenmiş sayılır. Ceza olarak yenilen takım yenen takımı sırtlarına alarak istenilen yere kadar taşır. Sarıkeçili Yörüklerde sırta bindirmeye "hobuçlamak" denmektedir. Ancak oyun çok tehlikelidir. Metin sivri uçlu olması, çomak ile çok sert vurulması karşı tarafta bulunan kişilerin vücutlarına zarar verebilmektedir.

3.1.6. Karanlık çeliği (kara çelik): Hava karardıktan sonra oynanan bir oyundur. Sekiz ya da on çocuk toplanır. Oyun için gündüz hazırladıkları malzemeleri getirirler. Normal çelikte kullanılan malzemeler kullanılır. Ancak oynama şekli biraz farklıdır. Yükselti yapması için yere iki tane taş konulur. Çelik bu taşların üzerine koyulur. Ortaya da bir taş konur. Bu taşa "mandak" denir. Bir kişi çeliği elindeki çomak ile havaya doğru en uzağa atar. Bütün çocuklar gecenin karanlığında kaybolan çeliği bulmaya çalışır. Bulan kesinlikle bulduğunu belli etmez. Belli etmesi halinde diğer bütün çocuklar çeliği alabilmek için bulan kişinin üzerine atlarlar. Bulan kişi diğer arkadaşlarına hissettirmeden, sanki yerde hala çeliği arıyormuş gibi davranarak orta taşının olduğu yere "mandağın olduğu yere" doğru gelmeye çalışır. Başlangıç noktasına gelip taşlara elindeki çeliği değdirirse sayı almış olur. Çeliği tekrar atma hakkı da bu kissiye geçer (İbrahim Bacak, Musa Candan ve Nedim Candan, 2015).

3.1.7. Kızgın taş oyunu: Oyun gece karanlığında oynanmaktadır. Ortaya bir ateş yakılır. Oyunda kullanılacak olan taş bu ateşin içerisinde 1sıtılır. Bir kişi bu taşı karanlığın içerisine doğru firlatır. Oyuncular hızla koşup taşın düştügü yeri bulmaya çalışırlar. Çalının, dikenin içerisi el yordamı ile kontrol edilir. Atılan taş sıcak olduğu için el yordamı ile yerde bulunan sıcak taş aranır. Taşı bulan kesinlikle sesini çıkartmaz. Sanki yerde taşı arıyormuş gibi yapmaya devam eder. Diğer oyunculara hissettirmeden kızgın taşın ilk atıldı̆̆1 yere doğru gitmeye çalışır. Diğer oyuncular durumu fark eder ise taşı elinde tutan kişinin üzerine çullanıp elinden kızgın taşı almaya çalışırlar. Kızgın taşı ilk önce kim ilk atıldığı noktaya getirirse sayıyı o alır. Kendi aralarında belirledikleri hedef puana ulaşan ilk kişi oyunun galibidir.

3.1.8. Tengelen: İki kişi arasında oynanan bir oyundur. $30-40 \mathrm{~cm}$. uzunluğunda sopa temin edilir. İlk önce oyunculardan biri elindeki sopayı uzağa firlatır. Diğer oyuncu atılan sopaya kendi sopasını değdirmeye çalışır. Kim diğerinin sopasına kendi sopasını değdirirse oyunu o kazanmış olur. Sarıkeçili Yörüklerde kazanmaya "ütmek" denilir. İbrahim Bacak, şimdiki çocukların bu oyunu oynamadığını ve hatta adını dahi bilmediklerini anlatarak üzüntüsünü dile getirmektedir. 
Büyükșahin, F. (2018). Kaybolan çocuk oyunlarının kültür ve çevre bağlamında incelenmesi: Sarıkeçili yörük örneği. Journal of Human Sciences, 15(2), 881-892. doi:10.14687/jhs.v15i2.5063

3.1.9. Domalan eşek: Oyun sekiz kişi ile oynanmaktadır. Ebe olan dört kişi birbirlerine kaba etlerini dayarlar. Birbirlerinden kopmamak için sağlarında ve sollarında bulunan arkadaşlarının bacaklarını kolları ile kavrarlar. Diğer dört kişi ebe olanların üzerinden atlamaya çalışırlar. Başarılı bir şekilde atlamayı başarırlar ise tekrar atlama hakları olur. Başaramazlar ise atlayan grup ebe olur ve diğer grupla yer değiştirirler. Oyun bıkana kadar bu şekilde devam eder.

3.1.10. Cingırtlak: 8-10 metre uzunluğundaki ladin ağacindan 'toru' denilen genç bir ladin bulunup çocuklar tarafindan kesilir. Budakları keserle düzeltilir. Ağaç kabuğu kesinlikle soyulmaz aksi takdirde ağaç gövdesi sakızlı bir yapı alır. Çocukların elbiseleri ve elleri sakız olur. Yöresel ifadeyle ellerinin avuçlarının "sak sak" olacağı şeklindedir. Ağaç gövdesinin orta denge noktasına gelen kısmı oyulur. 3 metrelik sağlam kuru bir ağaç gövdesinin uç kısmı sivriltilerek yaklaşık bir metresi toprağa gömülecek şekilde sağlamca yere dikilir. Kot fark1 olması için mümkünse bir tepenin yamacına dikilir. Daha önce hazırlanmış olan ana gövdenin oyuğuna tereyağı ile kömür tozu sürülür. Kömür tozunun sürülmesinin sebebi, ana gövdenin yere sağlamca dikilen odun parçasının üzerine yerleştirilip bu parçanın üzerinde döndürüldügüünde ses çıkartması içindir. Ana gövdenin her iki uçlarına çocuklar oturduğunda ana gövdenin üzerinden düşmemeleri için el tutamakları çivilerle çakılır. Bütün bu işlemler bittikten sonra ana gövde yere dikilmiş olan sırı̆ın üzerine oturtulur. Eşit sayıda çocuk ana gövdenin uçlarına binerler. Daha önceden sürülmüş olan kömür tozunun çıkarttı̆̆1 gıcırtı eşliğinde ana gövde çevrilmeye başlanır. Kot farkı olması nedeniyle yamacın olduğu kısma gelindiğinde heyecanın artmasından çocuklar neşeyle çığlıklar atarlar. Hem çığlığı duyan hem de cingırtlağın çıkarttı̆̆1 gıcırtıyı duyan çocuklar cingırtlağın yanına gelirler. Onlar da eğlenceye katılırlar. 3.1.11. Yüksük oyunu: Meşe palamudunun üzerinde bulunan şapka kısmı doğal çevreden toplanmaktadır. Sarıkeçili Yörükler bu meşe palamudunun şapkasına 'yüksük' demektedir. Doğal çevrenin sunmuş olduğu imkanlardan oyun icat etmektedirler. Gündüz davarı gütmeye giderken arkadaşını gören yörük, ona meydan okumakla oyun başlar. "boyn Mehmet senin tras vaktin gelmiş. Mehmet de Cemal asil senin turass vaktin gelmis. Akșama delikanlyysan ....(falanca) saatte gel de seni meydanda traş edeyim.” diye sözlü atş̧malarda bulunurlar. Akşam karşl1ıklı söz verilen vaktin gelmesi iple çekilir. Meydanda kuru odunlar yakılır. Yakılan odun ateşinin parıldaması için içerisine piynar dalı atılır. Bu piynar, sanki yıldızların göz kırpması gibi ateşin havada parlamasını, kıpraşan kıvılcımlar çıkarmasını sağlar. Oyuncular kazandıkları takdirde rakip oyuncunun yüzünü tıraş etmek için önceden hazırladığ1 sürpriz traş malzemesini yanında getirir. Oyunun bitiminde kazanan rakibinin yüzünü elinde bulunan malzeme ile tıraş edecektir.

Yüksük oyunu için yedi adet palamut şapkası toplanır. Bir tane yüksüğün altına daha önceden belirlenmiş bir nesne saklanır. Yedi yüksük birbirine karıştırllır. Diğer oyuncu saklanılmış olan nesneyi bulmak için yüksüklerden bir tanesini seçer. Yüksügü kaldırıp altını açar bakar. Bulamaz ise aramaya devam eder. Her yüksüğü kaldırıp bulamayışında nesneyi saklayan kişinin hanesine belirlenmiş olan sayı yazılır. Birinci yüksüğ̈ kaldırıp bulamaz ise saklayana 15 puan, ikinci yüksüğü kaldırıp bulamaz ise saklayana 12 puan ve üçüncü yüzüğü kaldırıp bulamaz ise 7 puan daha kaydeder. Bulmaya çalışan oyuncu ilk açışta nesneyi bulur ise 15 puanı kendi hanesine kaydeder. Aralarında anlaşmış oldukları toplam puana ilk ulaşan kişi oyunu kazanır. Oyun kalabalıkta daha çok heyecanlı hale gelir. İzleyicilerin yarısı bir tarafı, diğerleri ise diğer tarafı tutarlar. Kalabalık da fikrini söyleyerek saklı nesneyi bulmasına yardım eder. Diğer topluluk da rakiplerinin kafasını karıştırmaya çalışır. Bazen oyuna "deve oyunu" da denir. Yüksükler deve olarak adlandırllır. Arayan kişi "bizim deve hangisi acaba, yoksa bizim deve kurtlanmaya $\mathrm{m} 1$ gitti” şeklinde oyunu dillendirilir. Oyunda toplanılan puan ile genellikle yüz puana ulaşılmaya çalışlır. Yüz puana ulaşan oyuncu oyunu kazanır ve tıraşa başlar. Önce ellerindeki yüksüğ̈̈ karşısındaki rakip oyuncunun yüzüne sürer. Yüksük pütürlü bir yapıya sahip olduğu için yüzü acıtmaktadır. Sürpriz tıraş malzemelerinde bazen bir kömür vardır. Rakibinin yüzünü 'tıraş ediyorum' diye kömür ile tamamen siyaha boyar. Seyirciler için bu an çok keyiflidir. Bazen yüzü daha çok tahriş edip acıtsın diye, çam yaprakları toplanıp birleştirilir. Rakip oyuncunun yüzüne ‘tıraş ediyorum' diye sürülür. Bazen de yerde bulunan kül veya toprak çamur haline getirilir ve kaybedenin yüzüne sürülür. Bu karışımı berberin sabunu olarak kabul ederler. Balta, tahra, satır da ustura kabul edilir. Yüz traş edilmek için uğraşılır. Parfüm olarak 
Büyükșahin, F. (2018). Kaybolan çocuk oyunlarının kültür ve çevre bağlamında incelenmesi: Sarıkeçili yörük örneği. Journal of Human Sciences, 15(2), 881-892. doi:10.14687/jhs.v15i2.5063

keçi gübresi sürülür. Berberde bulunan bütün materyaller burada kullanıllır. Buna benzer daha birçok eziyet edilir. Kaybeden kesinlikle ses çıkartmaz ve cezasına razı olur. Halil Öksüzoğlu bu oyun ile ilgili bir macerasını şöyle anlatmaktadır.

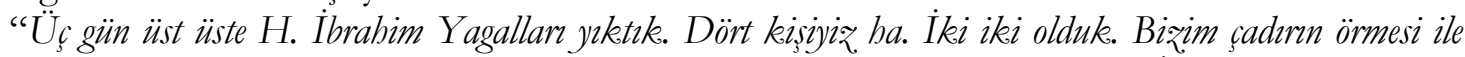
H. İbrabim'in dizlerini bağladim. Oturttum. Gözelce tras ettim. Yandanlan ikisini. H. İbrabim bir tane gemi

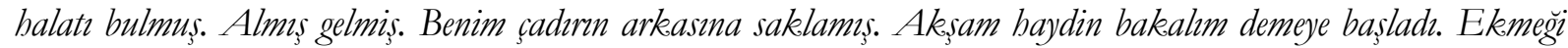
yiyverdik. Gene oynamaya başladık. Bunlar biæi ynktı orda. Bi de baktım biæim çadırn içerisine goca bir halat ginğ girdi. Ellerimiz̨i ayaklarmı̨ gözelce bir birine bağladılar. İki arkadaş oturduk. Ben buna çuldan firça yaptımıdı. Yü̊ünü daha çok actsm kellı batsm diye. Bu ne etti. Çam dalmm ucundaki sivri yeri girmıs. Onu dürtüyor. Haksiglle deyil mi."

3.1.12. Yalak (çukur) oyunu: İki kişi ile oynanır. Her oyuncu için beş yalak (çukur) açılır. Her oyuncunun on taşı vardır. Sıra ile yalaklara taşlar yuvarlanır. Önemli olan yalakta tek taş bırakabilmektir. İlk oyuncu yalağın birisine taşını atar. Rakip oyuncu da aynı yalağa kendi taşını düşürmeye çalışır. Böylece rakibin taşı yalakta tek kalmamış olur. Tek bırakmayı başaran yalaklarda bulunan taşları toplar. Bu esnada rakip oyuncunun taşı bitmiş olur ise taşları toplayan diğer oyuncu "Git dilen gel. Ben sana taşımı vermiyorum" der. Bu durumun üzerine rakip oyuncu yeniden taş toplar ve oyuna devam ederler.

3.1.13. Arka turası:_Arka turası oynayacaklar bir çadırın içerisinde toplanır. Sayı önemli değildir. Kaç kişi oynamak isterse oyuna katılabilir. Kalabalık olması oyunun daha zevkli hale gelmesini sağlar. 'Balık battı' oyununda kullanılan tura burada da kullanılmaktadır. Oyuna katılanlar daire olacak şekilde yere otururlar. Ebe olan kişi turayı eline alıp daire şeklinde bulunan arkadaşlarının arkasında dönmeye başlar. Turayı herhangi bir arkadaşının arkasına bırakır. Oyuncu turanın arkasına bırakıldığını fark etmez ise, ebe o kişiye türlü eziyetler etme hakkına sahip olmuş olur. En hafif ceza, ebeyi sırtına alarak daha önceden belirlenmiş yere kadar götürüp getirmesi gerekmektedir. Cezayı çeken kişi ebe olma hakkını da elde etmiş olur. Turayı arkasında fark eden kişi ebeyi kovalamaya başlar. Kovalama, ebenin boşalan yere oturmayı başarmasına kadar devam etmektedir. Ebe, boşluğa oturamaz ise turayı elinde bulunduran oyuncu istediği kadar ebeyi dövme hakkına sahiptir. Ebe kaçmaya devam eder. Yeni ebe turayı elinde bulunduran kişi olur. Oyun, bikılana kadar kendi aralarında dönmeye devam eder.

3.1.14. Deve kurdu: Oyuncular ikiye ayrllırlar. Birinci grup deveyi oluşturacak ekiptir. İkinci grup ise kurt olmaktadır. Deveyi oluşturan kişiler arka arkaya dizilirler. Herkes bir önündekinin elbisesinden tutar. Deve kervanının bir bekçisi olur. Bekçide tura bulunmaktadır. Kurt sürüsünü oluşturan grubun amacı deve kervanından birer birer deve çalarak kervanı devesiz birakmaktır. Kurtlar, doğadaki gibi uluma sesi çıkartırlar. Kurt grubu deve kervanından bir oyuncuyu çekmeye çalıştıkça bekçi elindeki tura ile onları dövmektedir. Tura ile vurduğu kişinin ismini söyler. Böylece o kişinin deve kervanından aldığı oyuncu olsa bile vurulduğu için almış kabul edilmez. Ama ebe tarafindan turalanmayan kişi, develerden birisini çalarsa o kişi oyundan çıkar. Tura yiyen kurdun oyuna devam etme hakkı vardır. Sadece turayı yediği için canı acımıs olur. Tüm develeri almayı başaran kurtlar, kervan bekçisinin üzerine atlarlar. Ve bekçiyi yere yıktıklarında oyunu kazanmış olurlar. Kurt grubu ile deve kervanını oluşturan grup yer değiştirerek oyuna yeniden başlarlar. Oyun, bıkana kadar bu şekilde devam etmektedir.

\section{Sonuç:}

Kültür, çevre ile gelişim ve değişim sürecine girmektedir. Çevre, etrafımızı kuşatan her şeydir. Doğal çevrede bulunan canlı ve cansız varlıkların korunduğu gibi kültürün korunması da çevrenin bir unsuru olarak oldukça önemlidir. Kültürlerin değişim sürecine etki eden başlıca ana nedeni, sosyo-ekonomik yapılar oluşturmaktadır (Büyükşahin ve Güneş, 2016). Bununla birlikte çevre, kültürün ve çocuk oyunlarının var olması ve yaşaması için önemli bir etkendir. Zira çevresel faktörler, kültürün değişmesine etki eden çok önemli unsurlar barındırmaktadır. Bu araşturmada çevresel faktörlerin kültürü değiştirmekte ne denli önemli olduğu ortaya çıkmıştır. Bu bağlamda çevrenin koruma altına alınması kapsamında sadece ekolojik çevrenin düşünülmesi yanlış olacaktır. 
Büyükşahin, F. (2018). Kaybolan çocuk oyunlarının kültür ve çevre bağlamında incelenmesi: Sarıkeçili yörük örneği. Journal of Human Sciences, 15(2), 881-892. doi:10.14687/jhs.v15i2.5063

Doğal çevrenin bir üyesi olan insan ve insanın oluşturduğu yaşam pratiklerinin bütününden oluşan kültürün de koruma altnna alınması gerekmektedir. Bu koruma somut kültür ve somut olmayan kültür başlığı altında iki kapsamda ele alınabilir. Sarıkeçili Yörüklerin sosyo-kültürel yapıları, somut olmayan kültürel miras kapsamına alınma çalışmaları 2009 yılından günümüze kadar devam etmektedir. Çocuk oyunlarının da bu kapsamda koruma altına alınmasının oldukça önemli olduğu değerlendirilmektedir.

Her ne kadar kapalı toplumlar açık toplumlara oranla daha geç kültürel bozulmalara uğrasa da gelişen şartlara ayak uydurma zorunluluğu, yaşam pratiklerinde değişiklikler meydana getirmektedir. Bulut (2016)'un da belirttiği gibi; bulundukları ortama bağlı oluşturulan yaşam pratiklerinin izole edilmesi ve bunun sürdürülmesi hiçbir toplum tarafindan gerçekleştirilememiştir. $\mathrm{Bu}$ açıdan bakıldığında Sarıkeçili Yörüklerin kültürel yapılarında değişimler olması da elbette kaçınılmaz bir gerçektir. Sarıkeçili Yörüklerin yaşam alanlarının her geçen gün ellerinden alınarak birbirlerinden oldukça uzak alanlara istihdam edilmeleri, teknolojinin gelişmesi, çocuk sayısının geçmiş yıllara oranla çok daha az olması, yeni yetişen neslin göçebe yörük yaşamı terk ederek yerleşik hayata geçmesi, kişi başına düşen iş yükünün geçmişe oranla çok daha fazla artması ve buna bağlı olarak çocukların çok daha erken yaşlarda olgunlaşmak zorunda kalması değişimin son otuz yılda çok hızlı gerçekleşmesinin en önemli etkenleri olarak görülmektedir.

Çocuk oyunları, çocukların bir birleri ile daha sıkı iletişim kurmalarına (Esen, 2015) kaynaşmalarına dostlukların ve arkadaşlık bağlarının kuvvetlenmesine etki eden en doğal ve sık tekrar edilen eğlence araçlarıdır. Ancak çocukların kişisel gelişimine pozitif katkıda bulunan oyunların oynanabilmesi için zamana, mekana ve çocukların bir arada olabilmesine ihtiyaç vardır. Şartlardan birisinin yok olması durumunda toplu oynanan oyunların kaybolması kaçınılmaz görülmektedir. Sarıkeçili Yörüklere toplu yaşam alanları verilmesi halinde bu topluluk Orta Asya'dan Anadolu'ya taşımış oldukları kültür birikimlerini ve çocuk oyunlarını yaşatmaya devam ettirebileceklerdir. Toplu yerleşim için Sarıkeçili Yörük Derneği, ilgili bakanlıklara gerekli girişimlerde bulunmuş ve olumlu geri dönüşler almışlardır. İlgili bakanlıkların konuyu görev bilip takip etmeleri halinde yörük kültürünün ve çocuk oyunlarının gelecek nesillere aktarılması oldukça kuvvet bulacaktır. Gelecek nesillerin temsilcileri olan çocukların bedensel gelişimleri kadar ruhsal gelişimlerini de pozitif yönde etkileyerek sağlıklı bir neslin gelişmesine katkı sağlayacaktır. Ankara Altınköy Açık Hava Müzesi örneğindeki gibi bir uygulama yapılması halinde ise, yerli ve yabancı ziyaretçilerin dikkatini çekecek ve ülkeye ek gelir sağlayacaktır.

\section{Kaynakça}

Akdemir, E. (2013). Avrupa Birliğinde Kimlik, Kültür Tartısmalar ve Türkiye. Bursa: Ekin Yayınları.

Aman, F. (2012). Bronislaw Malinowski'nin Kültür Teorisi. Uludağ Üniversitesi İlabiyat Fakültesi

Dergisi, Cilt: 21, Sayz: 1, 135-151.

Barzun, J. ve Graff, H. F. (1996). Modern araştırmacı. (F. Dilber, Çev.) Popüler Bilim Kitaplar (4. bs.). Ankara: TÜBİTAK.

Bulut, M. (2016). Kırsal Turizm Kapsamında Dönüşen Gelenekler: Turizm Köyü Örneği. Journal of Human Sciences, Volum:13, Issue:3, 4370-4379.

Bulut, M. (2017). Media, Migration and Crime: Syrian Refugies. International Journal of Advenced Research (IJAR), 927-932.

Büyükşahin, F., Güneş, S. G. (2016). Geleneksel Ekolojik Bilginin Önemi: Sarıkeçili Yörük

Örneği. Hacettepe Üniversitesi Sosyolojik A rastorma E-Dergisi,

http:/ / wnw.sdergi.hacettepe.edu.tr/ makaleler/FerhatBuyuksabinGulGunes.pdf.

Büyükșahin, F. (2017). Tarih Ekseninde Yörüklerin Atası Olan Oğuzların İncelenmesi. I. Uluslararası Türklerin Dünyası Sosyal Bilimler Sempozyumu, (s. 431-443). Antalya.

Büyükşahin, F., Güneş, G. (2017, Mart 30). Pastoral Göçebe Toplumlar ve Kültürel Peyzaj Korumanın Önemi . JRTR, 4(1), 36-48.

Corner, J. (1995). Kültür. Marmara İletisim Dergisi, Sayı: 9, 307-310. 
Büyükşahin, F. (2018). Kaybolan çocuk oyunlarının kültür ve çevre bağlamında incelenmesi: Sarıkeçili yörük örneği. Journal of Human Sciences, 15(2), 881-892. doi:10.14687/jhs.v15i2.5063

Deer, J. (1954). İstep Kültürï.

Esen, M. A. (2015). Geleneksel Çocuk Oyunlarının Eğitimsel Değeri ve Unutulmaya Yüz Tutmuş Ahıska Oyunları.Uludağ Üniversitesi Eğitim Fakültesi Dergisi Volume: 21, Issue: 2, s. 357367.

Girard, R. (2010). Kültürün Kökenleri, Çev: Mükremin Yaman, Ayten Er. Ankara: Dost Kiabevi Yayınlar1.

Kafesoğlu, İ. (1987). Türk Bozkır Kültürü. Türk Kültürünü Araştırma Enstitüsü.

Karcıoğlu, F. (2001). Örgüt Kültürü ve Örgüt İklimi İlişkisi. İktisadi ve idari Bilimler Dergisi, Cilt: 15, Sayz: 1-2, 265-283.

Kutlu, M. M. (1992). Yaşayan Bir Alt-Kültür Geleneği: Anadolu Göçer Kültürü. IV . Milletlerarası Türk Halk Kültürü Kongresi (s. 1-9). Ankara: Feryal Matbaas1.

Kutlu, M. M. (2000). Göçerlerde Mekansa Düzenleme: Çadır ve Ev İlişkisi. Anadolu ve Rumeli'de, 211-216.

Oğuz, E. S. (2011). Toplum Bilimlerinde Kültür Kavram1. Edebiyat Fakültesi Dergisi, Cilt 28, Sayz: 2, 123-139.

Peters, T. J., Waterman, R. H. (1987). Yönetme ve Yükseltme Sanat, Çev: Selami Sargut, Bilimsel Sorunlar Diఇisi.

Sayılır, Ş. B. (2012). Göçebelik, Konar-Göçerlik Meselesi ve Coğrafi Bakımdan Konar-Göçerlerin Farklılaşması. Türk Dünyası Inceleme Dergisi XII/ 1, 563-580.

UNESCO. (1982). Mexico City Declaration on Culturel Policies. http:/www.portal.unesco.org/culture/en/ adresinden alınmıştır. E. T. 07.08.2017.

Weber, C. (1991). International Relations Theory: A Critical Introduction. Londra: Routledge.

\section{Extended English Summary}

Culture relates the process of development and change with the environment. The environment is everything that surrounds us. It is very important to protect the cultures as an element of the environment, as well as protecting the living and non-living assets in the natural environment. It constitutes the main cause of socio-economic structures affecting the cultural change process. However, the environment has an important influence on the existence of cultures and children's games. Because environmental factors have very important effects on cultural change. In this research, it is revealed how important environmental factors are to change the culture. In this context, it would be wrong to consider only the ecological environment within the scope of protecting the environment. The people, who are the members of natural environment, and the culture which is formed with the whole life practices that people experienced must also be protected. This protection can be dealt with in two contexts under the titles of tangible culture and non-tangible culture. The studies on the socio-cultural structures of the Sarıkeçili Yörüks, including them in the scope of the intangible cultural heritage is still going on starting from 2009 to today. It is evaluated that it is very important to protect children's games in this context.

The necessity of keeping up with the evolving conditions, even if closed societies are later to suffer cultural degradation compared to open societies, causes changes in their life practices. The isolation and maintenance of the living practices that have been formed in accordance with their existence, has not been realized by any society. From this point of view, it is an inevitable fact that there are changes in cultural structures in Sarıkeçili Yörüks. But the main reasons for the rapid change in the last thirty years are; Sarkeçili Yörük 's habitats are taken from their hands every day and they are accommodated in areas far away from each other, the development of technology, the number of children is much less than the previous years, the new grown - ups leave the nomadic nomad life, and it is therefore seen as the most important factors that children have to mature at a much earlier age. 
There is a need for time and space for children to be able to play games that contribute positively to the personal development of children. If one of the conditions is lost, it is inevitable that the games played in bulk will be lost. If collective habitats are given to Sar1keçili Yörüks, this community will be able to continue the cultural accumulation and children's games they have carried from Central Asia to Anatolia. Sarıkeçili Yoruk Association has taken necessary initiatives to relevant ministries and received positive feedbacks for collective settlement. If the relevant ministries are aware of the mission and follow it, it will not be very difficult to transfer the nomadic culture and children's games to future generations. An example like the Ankara Altnköy Open Air Museum will attract domestic and foreign visitors and also provide additional income to the country.

The games of children in Sarıkeçili Yoruk community and the reasons of the disappearance of these games because of environmental factors are studied in this research. Time, place and children are required for the games, which have positive effect on children's personal developments, to be played. It is obvious that disappearance of the games played is inevitable in the case of loss of one of these conditions. Participant observation method which is one of the qualitative researches is used for this study. Detailed oral interviews have been done as the observation of the children's many games not been played recently in Sarkecçili Yoruk community, who is still having nomadic life, because of different effects. It is also observed that the children's games played until 1985s is remembered by the ones over middle ages and these games types are almost to forget. The places of this research consists of the small cities Silifke, Aydincik, Gülnar, Bozkır, Hadim, Seydişehir which are the habitats of Sarıkeçili Yoruk community having nomadic life. In this research, how the children's games, which have an important part for the culture to combine the community, were preserved and how it is blocked to hand down to generation to generation by the environmental factors are studied. Records about socio-cultural practices of recent nomads are created in the name of information for future generations by recording many of the children's games remembered today. 